\title{
Hypercalcemia with invasive pulmonary papillomatosis and microinvasive squamous carcinoma
}

\author{
Estelle Oertling*1, Philip Daroca ${ }^{1}$, Renee Hartz ${ }^{2}$, Susan McLellan ${ }^{3}$, Jason Lane ${ }^{4}$ \\ ${ }^{1}$ Department of Pathology and Laboratory Medicine, Tulane School of Medicine, New Orleans, LA, USA \\ ${ }^{2}$ Chicago Center for Myofascial Pain Relief, Chicago, IL, USA \\ ${ }^{3}$ Department of Internal Medicine, University of Texas Medical Branch, Galveston, TX, USA \\ ${ }^{4}$ Department of Anesthesiology, Tristar Centennial Medical Center, Nashville, TX, USA
}

Received: July 2, 2020

DOI: $10.5430 /$ crcp.v7n1p25
Accepted: August 16, 2020

Online Published: September 20, 2020

\begin{abstract}
Juvenile respiratory papillomatosis is a rare pediatric disease in which benign papillomata develop in the respiratory tract, most commonly involving the larynx and tracheobronchial tree. Invasive pulmonary papillomatosis is an aggressive form in which the papillomata extend into the lung parenchyma. We report a case of a 22-year-old man with a long-standing juvenile respiratory tract papillomatosis, initially diagnosed at age 2, who subsequently developed invasive pulmonary papillomatosis and underwent partial surgical resection for his pulmonary disease. Hypercalcemia complicated the patient's final hospitalizations. Human papillomavirus (HPV) typing performed on a laryngeal papilloma was positive for HPV 6/11. The lobectomy specimen revealed malignant transformation of invasive pulmonary papillomatosis characterized by the presence of microinvasive nests of squamous carcinoma. Immunohistochemical stain for parathyroid hormone on the invasive component was negative. Eventually, the patient succumbed to his disease and while the family refused post-mortem examination, Positron Emission Tomography (PET) performed during the patient's terminal course suggested the possibility of metastasis to liver and periaortic lymph nodes. There was no evidence of bony metastasis.
\end{abstract}

Key Words: Invasive pulmonary papillomatosis, Recurrent respiratory papillomatosis, Juvenile respiratory papillomatosis, Pulmonary papillomatosis hypercalcemia, Paraneoplastic syndrome, Invasive pulmonary papillomatosis and squamous cell carcinoma

\section{INTRODUCTION}

Juvenile recurrent respiratory papillomatosis is a severe and disabling disease characterized by the development of benign papillomata in the respiratory tract, especially the larynx, but in $2 \%-8 \%$ of patients the trachea and mainstem bronchi become involved. Relentless recurrence of bulky upper airway papillomata is the rule, leading to hoarseness, stridor and respiratory distress. Frequent bronchoscopic debulking is necessary to alleviate or prevent these symptoms, and there is often a need for tracheostomy. Papillomata spread through the airway by direct extension and aspiration of material into the distal airways during brochoscopic procedures or spontaneously. Less than $1 \%$ of patients develop pulmonary parenchymal involvement. ${ }^{[1]}$

Pulmonary parenchymal involvement can lead to malignant transformation into well-to-moderately differentiated squa-

*Correspondence: Estelle Oertling; Email: eoertlin@tulane.edu; Address: Department of Pathology \& Laboratory Medicine, 1430 Tulane Avenue, Box 8679, New Orleans, LA 70112, USA. 
mous cell carcinoma. Rare cases have been identified in patients with HPV papillomatosis. ${ }^{[2-10]}$ When malignant transformation occurs, there is usually a latent period of more than 15 years from initial diagnosis. ${ }^{[11]}$ Also, these patients initially demonstrate recurrent respiratory papillomatosis prior to two and a half years of age and require frequent papilloma debulking and tracheostomy. ${ }^{[7]}$

Furthermore, paraneoplastic hypercalcemia is a wellrecognized complication of carcinoma of the lower respiratory tract, especially of the squamous cell carcinoma type. The syndrome appears to be mediated by parathyroid hormone related peptides. The amino terminal of parathyroid hormone related peptides is similar with parathyroid hormone and likely exerts its systemic effects via parathyroid hormone receptors in the kidney and bone. ${ }^{[12]}$ There has only been one reported case of a patient with invasive papillomatosis and squamous cell carcinoma with paraneoplastic hypercalcemia. ${ }^{[13]}$ We describe a case of a young adult with juvenile respiratory papillomatosis progressing to invasive pulmonary papillomatosis and microinvasive squamous cell carcinoma, complicated by hypercalcemia.

\section{Case presentation}

A 22-year old African American man with no smoking history presented to an outpatient clinic complaining of lowgrade fever, increased sputum production, and weight loss. The patient's past medical history was significant for tracheobronchial papillomatosis diagnosed at age 2 when he presented with severe respiratory distress and required tracheostomy and excision of an obstructive laryngeal papilloma. Over the next ten years, he underwent frequent bronchoscopic excisions of papillomas from his oropharynx, larynx, and upper trachea. Pathologic examination of each specimen revealed squamous papilllomas with koilocytosis and no evidence of high-grade dysplasia. At age 14, he developed a "ring-like" lesion in his right mid lung field. Bronchoscopy revealed two small papillomas at the level of the mid-trachea but none more distally. He did well and had excellent exercise tolerance and no weight loss through his teens. He was also treated with a three-month course of acyclovir and his chest roetgenogram remained stable for the next year. However, he continued to require frequent excisions of pharyngeal and laryngeal papillomas which manifested as changes in his phonation.

At age 17, a repeat chest $\mathrm{x}$-ray demonstrated progression of cystic changes in his right lung. He was started on interferon therapy and the lesions stabilized and appeared to undergo peripheral fibrosis. Over the next year, he did not require any upper airway procedures. At the end of the interferon course, rigid bronchoscopy demonstrated no tracheal or main stem bronchial lesions and revealed only a small patch with HPV effect on his left vocal cord. He next developed dyspnea on exertion, at age 19, along with hoarseness. At the age of 21, a laryngeal papilloma was biopsied. A bronchial washing was suspicious for malignancy. HPV typing performed on the laryngeal papilloma was positive for HPV 6/11 and 31/33/51; HPV16/18 was not identified.

During his current presentation, the patient characterized his sputum as thick, white and often streaked with blood and white particles. He was unable to lie flat because of the constant necessity to cough and stated that he expectorated more than two cups of material daily. Recent medical history included two hospitalizations for treatment of right lung "abscess." During the second hospitalization, multiple attempts at percutaneous drainage of the "abscess" cavity were unsuccessful but yielded small amounts of fluid which grew alpha hemolytic Streptococcus. Cultures and stains were negative for fungus and acid-fast bacilli. At the time he was treated with clindamycin and intensive hydration. Pamidronate was also administered because his serum calcium level had increased from 12.8 to $14.6 \mathrm{mg} / \mathrm{dL}$ (normal range: 8.5 to 10.3 $\mathrm{mg} / \mathrm{dL})$.

The patient was admitted to the hospital for intravenous hydration, hyperalimentation, and parenteral antibiotics. Pertinent laboratory values included a white blood count of $22,000 / \mathrm{mm}^{3}$ (normal range: 4,000 to $11,000 / \mathrm{mm}^{3}$ ), hemoglobin of $9.6 \mathrm{~g} / \mathrm{dL}$ (normal range: 13.5 to $17.5 \mathrm{~g} / \mathrm{dL}$ ), calcium $16.8 \mathrm{mg} / \mathrm{dL}$ (normal range: 8.5 to $10.3 \mathrm{mg} / \mathrm{dL}$ ), and albumin $2.3 \mathrm{~g} / \mathrm{dL}$ (normal range: 3.4 to $5.4 \mathrm{~g} / \mathrm{dL}$ ). Other electrolytes and liver and renal function tests were normal. Chest X-ray showed complete opacification of the right upper lobe with a large air fluid level and bulging of the minor fissure. There was also consolidation of the right middle lobe and the superior segment of the lower lobe. Computerized tomography verified these findings and suggested that the cavitary lesion in the right upper lobe was necrotic tumor since the wall of the cavity was $2 \mathrm{~cm}$ thick in some areas. In addition, there were two new thin-walled cystic lesions in the left lung similar to those observed 8 years earlier in the right mid lung field. Therapy with piperacillin-tazobactam and clindamycin was initiated and the hypercalcemia was appropriately managed.

Four days after admission, the patient underwent right thoracotomy for diagnostic and therapeutic purposes. With left lung ventilation, the large cavity could not be collapsed or dissected off the chest wall. The hilus was approached by opening the cavity which was filled with "purulent material" in addition to a whitish material that did not appear to be pus. The latter was sent for frozen section examination and proved 
to be papillomatosis. The right upper lobe and superior segment of the lower lobe were replaced with tumor or confluent massive papillomas and were resected. The middle lobe and the remainder of the lower lobe were relatively spared and residual disease was clearly in the left chest.

The resected surgical specimen included the entire right upper lobe and the superior segment of the lower lobe. On sectioning, the lung was replaced by a solid, cystic, and papillary lesion. The cavitary component measured $5 \mathrm{~cm} \times 4$ $\mathrm{cm} \times 3 \mathrm{~cm}$ and was lined by papillary projections and solid areas impinged upon the visceral pleural surface.
Microscopically, pulmonary parenchymal papillomatosis essentially replaced the right upper lobe and the superior segment of the lower lobe, including the surgical margin of the latter. The lesion was both solid and cavitary with papillomas projecting into the cavitary component (see Figure 1A). Characteristic koilocytotic atypism, of the type associated with HPV cytopathic effect, was noted (see Figure 1B), and there was evidence of extension of the lesion into the alveolar spaces at the periphery of the solid components (see Figure 1C). There was no involvement of the bronchial margin of the resection or lymph nodes. Uninvolved areas of the lung showed secondary obstructive changes.

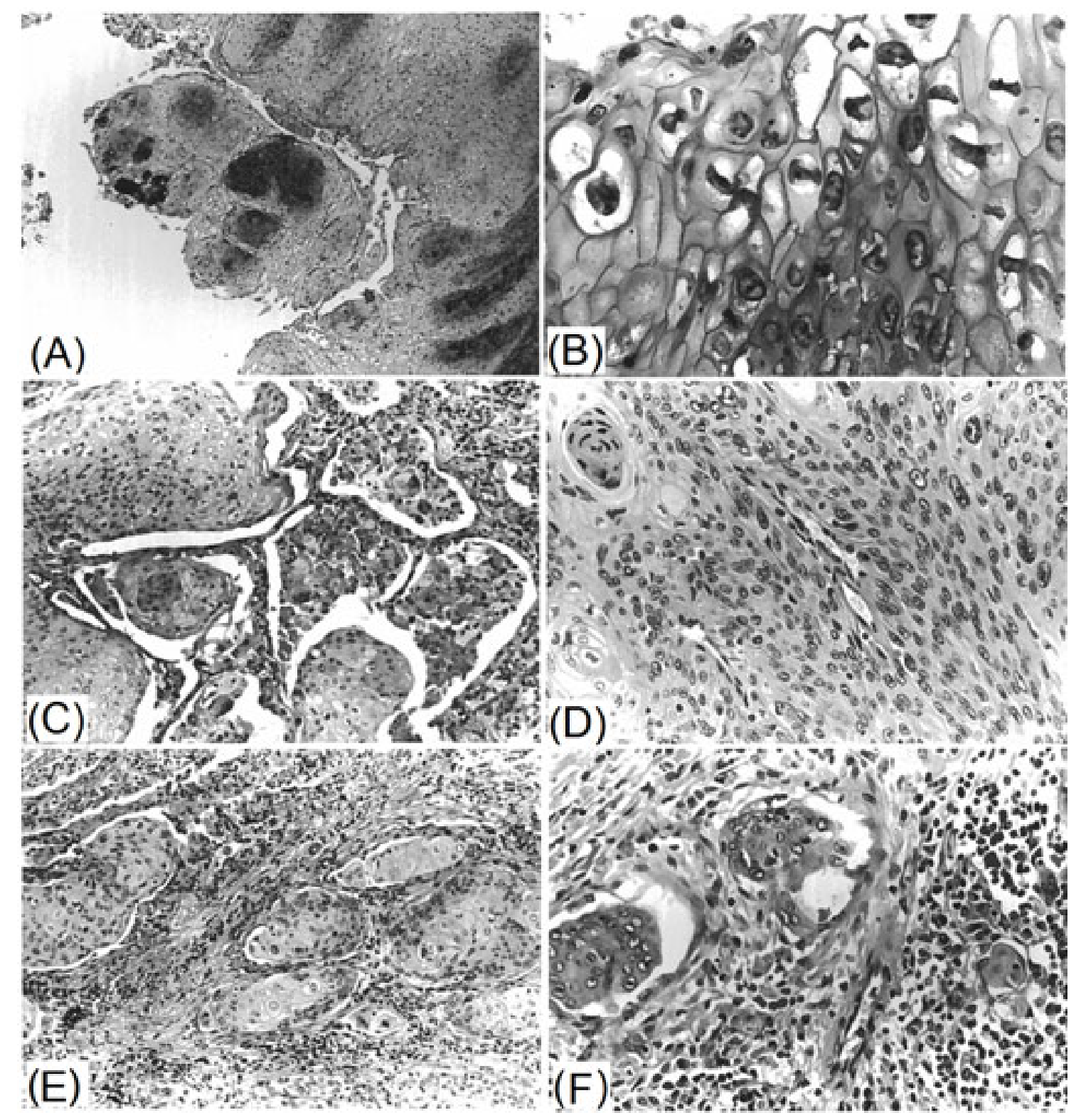

Figure 1. (A) Solid and cavitary lesion (H\&E, 100x). (B) HPV cytopathic effect (H\&E, 400x). (C) Extension into alveolar spaces (H\&E, 400x). (D) Squamous dysplasia (H\&E, 200x). (E) Microinvasive squamous cell carcinoma (H\&E, 100x). (F) Micronests of invasive squamous cell carcinoma without basement membrane (H\&E, 200x). 
Moderate to severe squamous dysplasia was present in some regions of the papillary and solid components of the lesion (see Figure 1D). In these areas, there were cellular crowding and disorientation, nuclear pleomorphism with coarse nuclear chromatin, mitotic figures, and intraepithelial squamous eddies. Foci consistent with microinvasive, well-differentiated squamous carcinoma were present in peripheral areas of the solid component (see Figures 1E and 1F). While an activated desmoplastic stroma was not identified in these foci, micronests were not encompassed by basement membrane material (see Figure 1F).

Because of the associated clinical hypercalcemia in the absence of demonstrable bone metastases, immunohistochemical stain for parathyroid hormone was performed on the pulmonary microinvasive lesion but was negative.

The patient did well postoperatively with thoracic epidural analgesia for pain control. His left lung remained expanded and the chest tubes were removed uneventfully. Prior to discharge, he was evaluated by the oncology service with the anticipation that he would be a candidate for chemotherapy, radiation, interferon or a combination of therapies when his functional status improved. His antibiotics were continued at home after discharge on postoperative day 11.

Two months later he returned again complaining of increasing cough and sputum production. He was not septic but was again hypercalcemic. He was treated with amoxicillinclavulanate, cidofovir, hydration, and pamidronate. He underwent flexible and rigid bronchoscopy and was found to have $80 \%$ obstruction of the distal trachea and $90 \%$ obstruction of the bronchus intermedius by papillomas. The masses were debrided and the bronchus intermedius was stented with a $15 \mathrm{~cm} \times 12 \mathrm{~mm}$ beveled stent. His symptoms improved markedly and he was discharged after being evaluated by radiation oncology service after whole body PET scanning suggested "right lung cancer".

Three months later he required tracheal stenting and repeat PET scan showed probable metastases to his liver and periaortic lymph nodes. He never improved sufficiently to receive chemotherapy or radiation and died at home one month after the tracheal stent had been placed. A postmortem examination was refused by the family.

\section{Discussion}

In our patient, as in most patients with recurrent respiratory papillomatosis, a laryngeal lesion was found to be positive for HPV types 6/11 but was also found to contain HPV types 31,33 , and 51 . While paraneoplastic hypercalcemia was clinically diagnosed in our case, it could not be corroborated by parathyroid hormone immunohistochemical staining. Additional aspects of our patient's case included bronchial washings which were suspicious for malignancy several years before he died, and a PET scan, performed 3 months after his lobectomy, which suggested hepatic metastasis. Although a post-mortem examination was refused by the family, clinical and pathologic findings at the time of death support malignant transformation.

HPV acquired through an infected birth canal is the causation of respiratory papillomatosis, with types 6 and 11 being most commonly identified. Guillou reported a patient with cavitary papillomatosis who developed malignant transformation after 33 years, followed by chest wall, vertebral, and peribronchial lymph node involvement. ${ }^{[14]}$ Molecular studies demonstrated HPV 11 DNA in both the squamous cell carcinoma and in two laryngotracheal papillomas, one of which had been excised 20 years previously. This patient did not smoke and had never undergone irradiation. Kerley et al. ${ }^{[1]}$ noted that because of the invasive nature of this disease, serial assessment for emergence of metastases (regional lymph nodes, ribs, soft tissues, diaphragm, and remote sites) is advised. Additional reports note that HPV 11 is most frequently followed by malignant transformation, followed by HPV 16/18. ${ }^{[15,16]}$ Furthermore, protein expression of p53, pRb, p21, and p16 in recurrent respiratory papillomatosis has also been reported. Lele studied four cases of juvenile-onset recurrent respiratory papillomatosis progressing to carcinoma in which HPV 11 was the only human papillomavirus type identified in all cases. ${ }^{[17]}$ Also, the dysplastic and carcinomatous areas demonstrated an increased p53 and pRb and decreased $\mathrm{p} 21$ expression. p16 protein expression was also expressed in all lesions.

To our knowledge, there is one other case of invasive pulmonary papillomatosis associated with paraneoplastic hypercalcemia of malignancy. ${ }^{[13]}$ In this case, a 14-year-old with aggressive recurrent respiratory papillomatosis infiltrative to lungs, intrapulmonary lymph nodes, and arteries developed metastatic squamous cell carcinoma to the heart, mediastinum, and extra-pulmonary lymph nodes. The patient also demonstrated paraneoplastic hypercalcemia of malignancy with a serum calcium of $14.6 \mathrm{mg} / \mathrm{dL}$. Parathyroidhormone immunohistochemical staining was not performed. Bone metastasis were not identified.

\section{CONFlicts OF INTEREST Disclosure}

We declare that we have no conflict interests. 


\section{REFERENCES}

[1] Kerly SW, Buchon-Zalles C, Moran J, et al. Chronic Cavitary Respiratory Papillomatosis. Arch Pathol Lab Med. 1989; 113: 1166-1169.

[2] Siddiqi T, Assar S, Lougee K, et al. Malignant transformation of recurrent respiratory papillomatosis: atypical presentation as right mainstem bronchus occlusion. Chest Journal. 2014; 145 (3): Supplement, 478A. https://doi.org/10.1378/chest. 1836553

[3] Xiao Y, Wang J, Han D, et al. A case of intrapulmonary spread of recurrent respiratory papillomatosis with malignant transformation. Am J Med Sci. 2015; 350 (1): 55-57. PMid:25423295. https://doi.org/10.1097/MAJ.0000000000000370

[4] Gerein V, Rastorgnev E, Gerein J. Incidence, age at onset, and potential reasons of malignant transformation in recurrent respiratory papillomatosis patients: 20 years experience. Otolaryngology Head and Neck Surgery. 2005; 132: 392-394. PMid:15746849. https://doi.org/10.1016/j.otohns.2004.09.035

[5] Rady PL, Schnadig VJ, Weiss RL, et al. Malignant transformation of recurrent respiratory papillomatosis associated with integrated human papilloma virus type 11 DNA and mutation of p53. The Laryngoscope. 1998; 108 (5): 735-740. PMid:9591556. https : //doi.org/10.1097/00005537-199805000-00021

[6] Orphanidou D, Dimakou K, Latsi P, et al. Recurrent respiratory papillomatosis with malignant transformation in a young adult. Respiratory Medicine. 1996; 90: 53-55. https ://doi.org/10.1016/ S0954-6111 (96) 90245-0

[7] Hammoud D, El Haddad B. Squamous cell carcinoma of the lungs arising in recurrent respiratory papillomatosis. Respiratory Medicine CME. 2010: 270-272. https://doi.org/10.1016/j.rmedc. 20 09.09 .021

[8] Mitsumoto GL, Del Carlo Bernardi F, Paes JF, et al. Juvenile-onset recurrent respiratory papillomatosis with pulmonary involvement and carcinomatous transformation. Autopsy Case Reports. 2018; 8(3): e2018035. PMid:30101139. https : //doi.org/10.4322. acr. 20 18.035

[9] Boudjemaa S, Leboulanger N, Dainese L, et al. Metastatic squamous cell carcinoma of the lung arising in a 12-year-old boy with juvenile recurrent respiratory papillomatosis of neonatal onset. Tuk Patholoji Derg. 2014; 30: 133-136. https://doi.org/10.5146/tjpath .2014 .01238
[10] Solomon D, Smith RRL, Kashima HK, et al. Malignant transformation in Non-irradiated recurrent respiratory papillomatosis. Laryngoscope. 1985; 95 (8): 900-904. PMid:4021682. https : //doi .org/ 10.1288/00005537-198508000-00003

[11] Cook JR, Hill A, Humphrey PA, et al. Squamous cell carcinoma arising in recurrent respiratory papillomatosis with pulmonary involvement: emerging common pattern of clinical features and human papilloma virus serotype associated. Mod Pathol. 2000; 13(8): 914 918. PMid:10955460. https://doi.org/10.1038/modpathol. 3880164

[12] Davidson LA, Black M, Carey FA, et al. Lung tumors immunoreactive for parathyroid hormone related peptide: analysis of serum calcium levels and tumor type. J of Pathology. 1996; 178: 398-401. https://doi.org/10.1002/(SICI) 1096-989 6(199604) 178:4<398: :AID-PATH496>3.0.CO;2-G

[13] Schnadig V, Clark W, Clegg T, et al. Invasive papillomatosis and squamous carcinoma complicating juvenile laryngeal papillomatosis. Arch Otolaryngol Head Neck Surg. 1986; 112: 966971. PMid:3741663. https://doi.org/10.1001/archotol.1 986.03780090062011

[14] Guillou L, Sahli R, Chaubert P, et al. Squamous cell carcinoma of the lung in a nonsmoking, non-irritated patient with juvenile laryngotracheal papillomatosis. Am J Surg Path. 1991; 15: 891898. PMid:1659237. https://doi.org/10.1097/00000478-1 99109000-00010

[15] Sakakura A, Yamamoto Y, Takasaki T,et al. Recurrent laryngeal papillomatosis developing into laryngeal carcinoma with human papilloma virus (HPV) type 18: A case report. J Laryngol Otol. 1996; 110: 75-77. PMid:8745789. https ://doi.org/10.1017/S00222 15100132773

[16] Doyle DJ, Gianoli GJ, Espinola T, et al. Changes in human papilloma virus typing in recurrent respiratory papillomatosis progressing to malignant neoplasm. Arch Otolaryngology Head Neck Surgery. 1994; 120: 1273-1276. PMid:7917213. https://doi.org/10.1001/ar chotol.1994.01880350079014

[17] Lele S, Pou A, Ventura K, et al. Molecular events in the progression of recurrent respiratory papillomatosis to carcinoma. Arch Pathol Lab Med. 2002; 126: 1184-1188. 